\title{
WHAT POLISH HOSPITAL HEALTHCARE WORKERS AND LAY PERSONS KNOW ABOUT COUNTERFEIT MEDICINE PRODUCTS?
}

\author{
Monika Binkowska-Bury ${ }^{1}$, Maja Wolan ${ }^{1}$, Paweł Januszewicz², Artur Mazur ${ }^{1}$, Zbigniew E. Fijałek $^{2}$ \\ ${ }^{1}$ Institute of Nursing and Health Sciences, Medical Department, University of Rzeszow, Poland \\ ${ }^{2}$ National Medicines Institute, Warsaw, Poland
}

\section{SUMMARY}

Aim: To report on Polish hospital health care workers' and lay persons' knowledge about counterfeit medicine products.

Materials and methods: Cross-sectional design was used. Two types of questionnaire survey about counterfeit medicine, separate for health care professionals and lay persons were completed by 201 physicians and nurses, and 450 adult Polish residents between October 2008 and January 2009.

Results: Physicians and nurses working in hospitals are more aware of counterfeit medicine than lay persons and more often notice the presence of drugs from unknown sources. Nearly $90 \%$ of physicians, $80 \%$ of nurses, and more than $40 \%$ of representatives of the lay persons had heard about the possibility of importing illegal medicine from Ukraine or China. The majority of medical workers does not know the procedure for reporting suspicious medicine and do not warn their patients against purchasing medicine from unknown sources.

Conclusions: Increase education of nurses and physicians about counterfeit medicine particularly including the procedure of reporting suspicious medicine from unknown sources. In practice, reinforce a role of nurses and physicians in warning their patients against purchasing medicine from unknown sources and educate them about possible health hazards and life risks.

Key words: counterfeit medicine, nurses, physicians, lay persons, hospital

Address for correspondence: M. Binkowska-Bury, Institute of Public Health, Medical Department, University of Rzeszow, Warzywna 1, 35-328 Rzeszow, Poland. E-mail: monika.binkowska@yahoo.com

\section{INTRODUCTION}

Illegal manufacturing and illegal supply of counterfeit medicines and dietary supplements is a growing problem in many countries. Trade in counterfeit medicines is increasing by around $15 \%$ a year in Europe and is rampant on the Internet (1-3). According to a report on EU Customs' enforcement in 2009, there were more than 11 million counterfeit medicines seized at EU borders, an increase of more than $400 \%$ in just three years (3). At the same time, more and more fatal incidents have been recorded by hospitals as lethal doses of these drugs are often taken by people using medicine illegally purchased from unknown sources, where no prescription is required or no warnings given about unwanted side-effects or interactions with other drugs.

According to the recent World Health Organization (WHO) definition, counterfeit drugs are pharmaceutical products that are deliberately and fraudulently mislabeled with the aim of concealing their composition and source (4). A broader definition also includes imitations of original products, which contain little or no active ingredients; relabeled series of drugs disqualified by the producer because of poor quality, but illegally launched without control, and expired drugs with a relabeled expiration date (5). Counterfeit drugs include both original and generic drugs, but most often they are designed for therapy of cardiovascular diseases, peptic ulcer disease, asthma, AIDS, tuberculosis, flu, tranquilizers, and so-called 'lifestyle drugs', e.g. slimming preparations or potency disorder medicine. Over the counter medicine (OTC) and dietary supplements are the second targets for counterfeiting (6).

Counterfeit medicine significantly threaten the whole health care system, risking patient health deterioration or even death and affecting the image of physicians, pharmacists, nurses, and private and government institutions. The violation of patient rights, intellectual property theft and tax fraud are problems inseparably linked with counterfeit medicine (7-9). Statistics published on 14 July 2011 by the European Commission show an amazing upward trend in the number of shipments suspected of violating intellectual property rights. In 2010, EU Customs registered around 80,000 cases, and valued more than 103 million products detained at the EU border. That figure has almost doubled since 2009 (10). In 2010, the total value of the world's counterfeit drug sales might even account for $\$ 75$ billion $(5,6,11)$.

In Poland, the phenomenon of counterfeit medicines is quite often described in the everyday and professional press as well as on the Internet. However, most of the information on this subject matter is disguised and unreliable. Detailed data on counterfeit medicines are difficult to obtain and there are difficulties in interpreting the available information. Because the scale of counterfeit medicines in Poland is not officially registered in government statistics, and only incidentally appears in the mass media or by accident as an additional plot in criminal cases, it would be interesting to examine whether professional health care workers understand and notice this problem in their everyday professional 
practice. Acquiring the opinion of lay persons of the scale of counterfeit medicines would also be helpful.

There are two important factors responsible for the global counterfeit drugs phenomenon in Central-East Europe. First, the insufficient knowledge about counterfeit medicine among professional health care workers and government administration, mainly regarding the police and customs service. Previous studies regarding East European countries - Bulgaria, Romania, Macedonia, Bosnia Herzegovina demonstrate that there is a lack of objective drug information and postgraduate education is not oriented on the $\mathrm{ED}$, and therefore, there is no guarantee for rational drug prescription and usage of drugs available on the markets (12).

Second, reluctance of pharmaceutical companies to publicize their data about counterfeit drugs. Although the pharmaceutical industry suffers multi-billion euro losses, it still unwillingly acts against illegal competition. Many companies do not want to publish reports on the counterfeiting of their products and do not share the information with the police or warn their patients. They are afraid that their image may be ruined, resulting in sales decreases. In turn, the police cannot justify concerted action since the crimes are insufficiently reported.

According to $\mathrm{WHO}$, there are 10 main factors favouring the existence of counterfeiting: lack of legislation; weak or absent drug regulatory authority, absence of legal mandate for licensing of manufacture, import of drugs, lack of enforcement of existing regulations, transactions involving many intermediaries, demand exceeding supply, high prices, sophistication of clandestine drug manufacture, inefficient cooperation between stakeholders, and lack of regulations by exporters and within free trade zones (1). Increasing online drug sales and parallel imports are also highlighted as the most important threats to safe trade $(1,2)$.

A separate issue is people's insufficient knowledge about the threats of buying drugs via the Internet, a major counterfeit drug distribution channel. In Poland, the scale of the threat was exposed by recent research that demonstrated that $42 \%$ of Polish residents believed drugs could be sold without any special limits, just like other products. Furthermore, every fifth person out of three-quarters of Polish residents in the past six months has bought OTC drugs from kiosks, local stores, or gas stations rather than in pharmacies*.

Government and health care workers together have an obligation to provide society with solutions to the counterfeit medicine problem. Health care workers are not only the most important source of information about proper pharmacotherapy, but also play a crucial role in detecting and preventing the distribution of counterfeit medicine.

The aim of the paper was to report on Polish hospital healthcare workers' and lay persons' knowledge about counterfeit medicine.

\section{MATERIALS AND METHODS}

The sample included 201 hospital health care workers (physicians and nurses) and 450 adult residents of Rzeszow (Poland). Rzeszow is located no further than $50 \mathrm{~km}$ from the Polish border with Ukraine (eastern border of Poland), or Slovakia (southern border of Poland). Excluded from the group of lay persons were: physicians, community nurses, the unemployed, and people under 18 years of age.

The study population was purposefully chosen. A proportional representation was also secured of different social groups of the south-east of Poland, which characterizes developed touristic and trade structures and is located on the main communication track linking Poland with Ukraine, the countries of the former USSR and Slovakia. According to statistical data of Subcarpathian Public Health Care Centre in 2008 in Sanok County, 159 physicians and 475 nurses were employed. Convenience sample of 99 physicians and 102 nurses as well as 450 adult residents of Rzeszow (Poland) was recruited. The study was carried out in Poland between October 2008 and January 2009.

The study was conducted using a questionnaire survey. Two separate questionnaire surveys were used, one for health care professionals and the other for lay persons. Both questionnaires consisted of 20 questions seeking to find out the opinions and level of awareness about the counterfeit problem in Poland. The survey aimed to discover respondents' views on:

- Awareness of the extent of the counterfeit medicines problem in Poland.

- Awareness of the threats that might be caused by fake medicines.

- Awareness of the scale of counterfeit medicines and dietary supplements sold outside pharmacies.

As a method of increasing reliability, a pilot study (August September 2008) was conducted among 40 nurses and 50 residents of Rzeszow. The results of this pilot study did not demonstrate structural defects of the tool. Statistical analysis conducted on this stage also did not demonstrate any defects.

The study was conducted for individual grant regarding research projects according to Directive No.100/2008 University of Rzeszow. The Commission for Bioethics at General Medical Council in Rzeszow approved the study, which is conducted in accordance with Helsinski Declaration. Participation in the survey was both voluntary and anonymous, and the research material was treated confidentially. The studied group was given instructions in a covering letter, followed by the questionnaires. The study was carried out in the presence of departmental nurses from Specialist Hospital in Sanok: Anesthesiology and Intensive Therapy Department, Internal Diseases Department, General Surgery Department, Orthopedics Department, and Pediatrics Department, and pollsters for lay persons. The return of completed questionnaires was accompanied by the confirmation of participation agreements.

The gathered data were analysed using the statistical package STATISTICA 9.0. The chi-squared test and test for fraction were used for statistical analysis.

\section{RESULTS}

Among 201 professional hospital health care workers studied there were 102 physicians (50.7\%) and 99 nurses (40.3\%). Women make up the majority $(66.7 \%)$. The age range was as follows: $30-39$ years $(42.8 \%) ; 40-49$ years $(37.3 \%)$; >50 years $(11.4 \%)$;

*According to data provided by the Public Opinion Research Centre (survey conducted in 2004 - If medicine than only in pharmacy, and 2007 - Shopping medicine habits of Poles) 
and $23-29$ years $(8.5 \%)$. More than half of hospital workers $(56.2 \%)$ come from rural areas. All studied physicians had higher education (100\%). The majority of nurses $(76.8 \%)$ had a secondary education and $23.2 \%$ had a higher education.

Among the studied adult population (450 people), women make up the majority (63.8\%). Almost half of respondents (47.6\%) were $18-30$ years old; $20.9 \%$ were $31-40$ years old; and $18.2 \%$ $41-50$ years old. The minority of respondents were over 50 years old (13.3\%). All respondents come from urban areas. Under half of studied people had a secondary education (46.2\%) with $33.6 \%$ having a higher education $33.6 \%$, followed by vocational education $(16.9 \%)$, and basic education $(3.3 \%)$.

To investigate the awareness of the counterfeit medicines sale in Poland, we first surveyed respondents on counterfeit goods including branded clothes, perfumes and fuel, and then medical products and dietary supplements. Although the analysis of the results showed that both health care professionals and lay persons are aware that sales of counterfeit goods occur in Poland, it also revealed differences regarding counterfeit medicines and dietary supplements. Lay persons have slightly worse awareness on the possibility of purchasing counterfeit medicines from unknown sources than health care professionals $(87.1 \%$ vs. $80.2 \%)$ (Table $1)$.

The vast majority of health care professionals and lay persons (99\% vs. $89.3 \%$ ) usually purchase medicine, vitamins and dietary supplements at pharmacies. However, we found that both physicians and nurses happen to purchase medicine and dietary supplements in places untypical for purchasing medicine e.g. kiosks and bazaars. Very seldom health care professionals and lay persons also purchase medicine from online pharmacies (Table 2).

In opinion of more lay persons than nurses and physicians, counterfeit medicines is already a problem in Poland $(82.5 \%$ vs. 70.9\%) (Table 3).

In the opinions of physicians, nurses and lay persons, the sale of counterfeit medicine will continue to grow in the future $(99 \%$ vs. $98 \%$ vs. $97.3 \%)$.
The results showed that medical workers are more aware than lay persons of the illicit trade of medicine or dietary supplements outside pharmacies. Bazaars or local markets are believed to be a trading channel in the opinion of $68 \%$ of medical workers and only $46.4 \%$ of lay persons ( $\mathrm{p}<0.001$ ). More healthcare professionals believed that it is possible to import medicine from Ukraine or China ( $83.5 \%$ vs. $43.8 \%)$; $(\mathrm{p}<0.001)$. Likewise, more health care professionals than lay persons believed that it is possible to purchase medicine such as Viagra outside a pharmacy $(76.1 \%$ vs. $53.8 \%)(\mathrm{p}<0.001)$ (Table 4).

From data obtained, most physicians and nurses estimated the share of counterfeit medicine bought via the Internet from uncertain sources as $10 \%$ ( $45.7 \%$ vs. $34.7 \%)$ or $50 \%(31.7 \%$ vs $37 \%)$. At the same time, data demonstrated that more than a half of the lay persons $(50.2 \%)$ and only $11.6 \%$ medical workers believed that $90 \%$ of medical sales in less developed countries were from unknown sources $(\mathrm{p}<0.001)$.

The majority of physicians $(73.5 \%)$ and almost $30 \%$ of nurses said that they do not warn patients against counterfeit medicines $(\mathrm{p}<0.001)$. Only $4.9 \%$ physicians and $19.2 \%$ nurses always inform patients about the problem of counterfeit medicine, and $3.9 \%$ physicians and $17.2 \%$ nurses do it only sometimes (Table 5).

Further analysis of the results showed that medical workers are not fully aware of the dangers of counterfeit medicine and do not know the procedure for reporting suspicious medicine (physicians $91.2 \%$; nurses $88.9 \%$ ). Only $8.8 \%$ of physicians and $11.1 \%$ of nurses know what to do in such a situation.

More than a half of these respondents have not encountered the problem regarding complications caused by medicine from uncertain sources (50.5\%). Only 3 physicians reported complications caused by medicine from uncertain sources.

As many as $65.8 \%$ of lay persons said that they had never been informed by physicians or nurses against purchasing medicine from unknown sources. Such information was obtained by only $34.2 \%$ of respondents.

Table 1. Opinions on counterfeiting goods in Poland (chi-square test)

\begin{tabular}{|c|c|c|c|c|c|c|c|c|c|}
\hline \multirow{2}{*}{\multicolumn{2}{|c|}{ Opinions }} & \multirow{2}{*}{\multicolumn{2}{|c|}{$\begin{array}{c}\text { Physicians } \\
\mathrm{N}=102\end{array}$}} & \multirow{2}{*}{\multicolumn{2}{|c|}{$\begin{array}{c}\text { Nurses } \\
\mathrm{N}=97\end{array}$}} & \multirow{2}{*}{\multicolumn{2}{|c|}{$\begin{array}{c}\text { Health professionals } \\
\qquad \mathrm{N}=199\end{array}$}} & \multirow{2}{*}{\multicolumn{2}{|c|}{$\begin{array}{c}\text { Lay persons } \\
\mathrm{N}=450\end{array}$}} \\
\hline & & & & & & & & & \\
\hline & & \multirow{2}{*}{$\begin{array}{l}\mathrm{N} \\
86\end{array}$} & \multirow{2}{*}{$\frac{\%}{84.3}$} & \multirow{2}{*}{$\begin{array}{c}\mathbf{N} \\
79\end{array}$} & \multirow{2}{*}{$\begin{array}{c}\% \\
81.4\end{array}$} & \multirow{2}{*}{$\frac{N}{165}$} & \multirow{2}{*}{$\begin{array}{c}\% \\
82.9\end{array}$} & \multirow{2}{*}{$\begin{array}{c}\mathbf{N} \\
166\end{array}$} & \multirow{2}{*}{$\frac{\%}{36.9}$} \\
\hline \multirow{3}{*}{$\begin{array}{l}\text { Have you ever face a problem or heard of } \\
\text { a possibility to buy renowned perfumes for } \\
\text { little money? }\end{array}$} & Yes & & & & & & & & \\
\hline & No & 16 & 15.7 & 18 & 18.6 & 34 & 17.1 & 284 & 63.1 \\
\hline & $p$ & \multicolumn{4}{|c|}{0.591} & \multicolumn{4}{|c|}{$<0.001$} \\
\hline \multirow{3}{*}{$\begin{array}{l}\text { Have you ever face a problem or heard of } \\
\text { a possibility to buy branded clothes e.g. } \\
\text { Adidas, Puma, Levis for little money? }\end{array}$} & Yes & 89 & 88.1 & 85 & 85.9 & 174 & 87.0 & 196 & 43.6 \\
\hline & No & 12 & 11.9 & 14 & 14.1 & 26 & 13.0 & 254 & 56.4 \\
\hline & $p$ & \multicolumn{4}{|c|}{0.635} & \multicolumn{4}{|c|}{$<0.001$} \\
\hline \multirow{3}{*}{$\begin{array}{l}\text { Have you ever face a problem or heard of } \\
\text { counterfeit fuel phenomenon? }\end{array}$} & Yes & 99 & 97.1 & 96 & 97.0 & 195 & 97.0 & 418 & 92.9 \\
\hline & No & 3 & 2.9 & 3 & 3.0 & 6 & 3.0 & 32 & 7.1 \\
\hline & $p$ & 1.000 & & & & 0.038 & & & \\
\hline \multirow{3}{*}{$\begin{array}{l}\text { Have you ever face a problem or heard of } \\
\text { counterfeit drugs or dietary supplements } \\
\text { phenomenon? }\end{array}$} & Yes & 90 & 88.2 & 85 & 85.9 & 175 & 87.1 & 361 & 80.2 \\
\hline & No & 12 & 11.8 & 14 & 14.1 & 26 & 12.9 & 89 & 19.8 \\
\hline & $p$ & \multicolumn{4}{|c|}{0.616} & \multicolumn{4}{|c|}{0.034} \\
\hline
\end{tabular}


Table 2. Places where medicine, vitamins and dietary supplements is purchased (test for fraction)

\begin{tabular}{|c|c|c|c|c|c|c|c|c|c|c|}
\hline \multirow{3}{*}{$\begin{array}{l}\text { Where do you usually } \\
\text { purchase OTC medicine, } \\
\text { vitamins or dietary } \\
\text { supplements? }\end{array}$} & \multirow{2}{*}{\multicolumn{2}{|c|}{$\begin{array}{c}\text { Physicians } \\
\mathrm{N}=102 \\
\end{array}$}} & \multirow{2}{*}{\multicolumn{2}{|c|}{$\begin{array}{c}\text { Nurses } \\
\mathrm{N}=99\end{array}$}} & \multirow{3}{*}{$\mathrm{p}$} & \multirow{2}{*}{\multicolumn{2}{|c|}{$\begin{array}{c}\text { Health professionals } \\
\mathrm{N}=201\end{array}$}} & \multirow{2}{*}{\multicolumn{2}{|c|}{$\begin{array}{c}\text { Lay persons } \\
\mathrm{N}=450 \\
\end{array}$}} & \multirow{3}{*}{$\mathrm{p}$} \\
\hline & & & & & & & & & & \\
\hline & $\mathrm{N}$ & $\%$ & $\mathrm{~N}$ & $\%$ & & $\mathrm{~N}$ & $\%$ & $\mathrm{~N}$ & $\%$ & \\
\hline Pharmacy & 102 & 100 & 97 & 98.0 & 0.153 & 199 & 99.0 & 402 & 89.3 & $<0.001$ \\
\hline Food store & 36 & 35.3 & 21 & 21.2 & 0.028 & 57 & 28.4 & 103 & 22.9 & 0.133 \\
\hline Supermarket & 41 & 40.2 & 16 & 16.2 & $<0.001$ & 57 & 28.4 & 131 & 29.1 & 0.856 \\
\hline Kiosk & 23 & 22.5 & 8 & 8.1 & 0.005 & 31 & 15.4 & 66 & 14.7 & 0.817 \\
\hline Herbal or healthy food store & 63 & 61.8 & 32 & 32.3 & $<0.001$ & 95 & 47.3 & 101 & 22.4 & $<0.001$ \\
\hline Gas station & 5 & 4.9 & 6 & 6.1 & 0.709 & 11 & 5.5 & 63 & 14 & 0.002 \\
\hline Bazaar & 0 & 0 & 4 & 4.0 & 0.043 & 4 & 2.0 & 14 & 3.1 & 0.429 \\
\hline Door-to door salesman & 0 & 0 & 1 & 1.0 & 0.313 & 1 & 0.5 & 1 & 0.2 & 0.513 \\
\hline Family and/or friends & 0 & 0 & 0 & 0 & $<0.001$ & 0 & 0 & 13 & 2.9 & 0.015 \\
\hline Online pharmacy & 2 & 2 & 4 & 4 & 0.406 & 6 & 3 & 31 & 6.9 & 0.048 \\
\hline
\end{tabular}

Table 3. Opinions on counterfeit medicine in Poland (chi-square test)

\begin{tabular}{|c|c|c|c|c|c|c|c|c|}
\hline \multirow{3}{*}{$\begin{array}{l}\text { Do you belive that } \\
\text { counterfeit medicines are } \\
\text { problem in Poland? }\end{array}$} & \multicolumn{2}{|c|}{ Physicians } & \multicolumn{2}{|c|}{ Nurses } & \multicolumn{2}{|c|}{ Health professionals } & \multicolumn{2}{|c|}{ Lay persons } \\
\hline & \multicolumn{2}{|c|}{$\mathrm{N}=102$} & \multicolumn{2}{|c|}{$\mathrm{N}=97$} & \multicolumn{2}{|c|}{$\mathrm{N}=191$} & \multicolumn{2}{|c|}{$\mathrm{N}=223$} \\
\hline & $\mathrm{N}$ & $\%$ & $\mathrm{~N}$ & $\%$ & $\mathrm{~N}$ & $\%$ & $\mathrm{~N}$ & $\%$ \\
\hline Yes & 81 & 79.4 & 60 & 61.9 & 141 & 70.9 & 184 & 82.5 \\
\hline No & 21 & 20.6 & 37 & 38.1 & 58 & 29.2 & 39 & 17.5 \\
\hline$p$ & \multicolumn{4}{|c|}{0.006} & \multicolumn{4}{|c|}{0.004} \\
\hline
\end{tabular}

\section{DISCUSSION}

This paper, to the authors' knowledge, is also the very first to deal with and analyse the knowledge on the presence of counterfeit drugs in illegal trade in Poland. Thus, it is difficult to compare our results with the results of others, since such studies simply do not exist; we have tried to verify them with the available information.

There are limitations to the present study. The survey questionnaires are not standardized research instruments, and the study sample represents the population of nurses, physician, and lay persons from one region. Thus, results of the study as to the generalization of its findings are limited. Nevertheless, the findings enhance the information on the knowledge about counterfeit medicine of relatively large group of nurses, physician, and lay persons at least from one region. Further studies are recommended.

Results of this study suggest disparities between health care workers and lay persons in understanding counterfeit medicines phenomenon.

Our findings revealed lesser awareness about the danger of purchasing illegal medicines or dietary supplements outside pharmacies among lay persons than among health care professionals. Polish people as well as many others in the Central-Eastern Europe are prone to purchase the fake drugs because the low cost of the drugs makes them very attractive to people with low monthly incomes. Polish people are at a particular disadvantage when it comes to purchasing these illegal drugs because there is no public awareness programme about purchasing drugs over the Internet (13)
Obtained data showed that health care professionals have lower levels of awareness about the scale of counterfeit medicines than lay persons. Unfortunately, the fact that counterfeit medicines trading and their use is underreported by Polish health care workers only promotes this trade. It is a role of the government, but also of physicians and nurses to introduce to patients issues related to counterfeit medicine. Since nurses and physicians should always be aware of counterfeit medicine harmful effects, especially in case of untypical reaction or lack of expected actions after taking medicine out of official distribution, it is important to increase their knowledge about it $(14,15)$.

Health care professionals are less aware of the threats posed by counterfeit medicines to patients' health. It is unacceptable that the majority of them does not inform patients about the dangers of counterfeit medicines and purchasing medicine from unknown sources or does not know the procedure for reporting suspicious medicine. A major lack of awareness about the scale of the counterfeit medicine problem and its consequences to health may somehow explain why health care professionals in Poland do not warn patients and, in general, prevent the use of counterfeit medicines. However, if this lack of awareness continues in the future, it will contribute towards an increase of counterfeit medicine trade in Poland. Therefore, phenomenon of counterfeit medicine in Poland should be introduced in educational programmes aimed at health care workers. Nurses and physicians should be trained how to share information on counterfeit medicine with patients. Adequate trainings of nurses and physicians and other health care workers by government as well as relevant agencies in detection of counterfeit drugs should be implemented in practice. 
Table 4. Opinions on the scale of selling counterfeit medicines in Poland (chi-square test)

\begin{tabular}{|c|c|c|c|c|c|c|c|c|c|}
\hline \multirow{2}{*}{\multicolumn{2}{|c|}{ Opinions }} & \multirow{2}{*}{\multicolumn{2}{|c|}{$\begin{array}{c}\text { Physicians } \\
\mathrm{N}=102\end{array}$}} & \multirow{2}{*}{\multicolumn{2}{|c|}{$\begin{array}{c}\text { Nurses } \\
\mathrm{N}=98\end{array}$}} & \multirow{2}{*}{\multicolumn{2}{|c|}{$\begin{array}{c}\text { Health professionals } \\
\mathrm{N}=\mathbf{2 0 0}\end{array}$}} & \multirow{2}{*}{\multicolumn{2}{|c|}{$\begin{array}{c}\text { Lay persons } \\
\mathrm{N}=450\end{array}$}} \\
\hline & & & & & & & & & \\
\hline & & \multirow{2}{*}{$\frac{N}{76}$} & \multirow{2}{*}{$\frac{\%}{74.5}$} & \multirow{2}{*}{$\begin{array}{l}\mathbf{N} \\
60\end{array}$} & \multirow{2}{*}{$\frac{\%}{61.2}$} & \multirow{2}{*}{$\frac{N}{136}$} & \multirow{2}{*}{$\frac{\%}{68.0}$} & \multirow{2}{*}{$\frac{N}{209}$} & \multirow{2}{*}{$\begin{array}{c}\% \\
46.4\end{array}$} \\
\hline \multirow{3}{*}{$\begin{array}{l}\text { *Have you ever seen medicine or dietary } \\
\text { supplements available at bazaar? }\end{array}$} & Yes & & & & & & & & \\
\hline & No & 26 & 25.5 & 38 & 38.8 & 64 & 32.0 & 241 & 53.6 \\
\hline & $p$ & \multicolumn{4}{|c|}{0.045} & \multicolumn{4}{|c|}{$<0.001$} \\
\hline \multirow{3}{*}{$\begin{array}{l}\text { *Have you ever heard of possibility of import- } \\
\text { ing medicine in demand e.g. vitamins or } \\
\text { dietary supplements from Ukraine, China etc.? }\end{array}$} & Yes & 91 & 89.2 & 76 & 77.6 & 167 & 83.5 & 197 & 43.8 \\
\hline & No & 11 & 10.8 & 22 & 22.5 & 33 & 16.5 & 253 & 56.2 \\
\hline & $p$ & \multicolumn{4}{|c|}{0.026} & \multicolumn{4}{|c|}{$<0.001$} \\
\hline \multirow{3}{*}{$\begin{array}{l}\text { *Have you ever heard of the possibility of } \\
\text { buying Viagra outside of pharmacy? }\end{array}$} & Yes & 85 & 83.3 & 68 & 68.7 & 153 & 76.1 & 242 & 53.8 \\
\hline & No & 17 & 16.7 & 31 & 31.3 & 48 & 23.9 & 208 & 46.2 \\
\hline & $p$ & \multicolumn{4}{|c|}{0.015} & \multicolumn{4}{|c|}{$<0.001$} \\
\hline
\end{tabular}

${ }^{*}$ Excluding an occupational aspect

Table 5. Opinions on warning against buying medicine from unknown sources (chi-square test)

\begin{tabular}{|l|c|c|c|c|c|}
\hline \multirow{2}{*}{$\begin{array}{l}\text { Have you ever in your professional practice } \\
\text { warned your patients against purchase of } \\
\text { medicine from unknown source? }\end{array}$} & \multicolumn{2}{|c|}{ Physicians } & \multicolumn{2}{|c|}{ Nurses } \\
\cline { 2 - 5 } & $\mathbf{N}=102$ & $\mathbf{N}=99$ & $\mathbf{2}$ \\
\hline No & $\mathbf{N}$ & 17.7 & 29 & 29.3 \\
\hline Rather no & 75 & 73.5 & 34 & 34.3 \\
\hline Rather yes & 4 & 3.9 & 17 & 17.2 \\
\hline Yes & 5 & 4.9 & 19 & 19.2 \\
\hline
\end{tabular}

Obtained data demonstrated that the majority of physicians was not able to state if ever in their work they had encountered complications caused by counterfeit medicines from unknown sources. This lack of awareness of the harmful effects of counterfeit medicines, especially in cases of unusual reactions or lack of expected reactions after taking medicine from unofficial distribution sources indicates the great need to improve awareness of this phenomenon. Much has been written about it in the world's literature. According to recommendations issued by the WHO's International Medical Products Anti-counterfeiting Task Force (IMPACT), nurses and physicians should always be aware of the counterfeit medicines phenomenon, especially unusual reactions to drug treatment, particularly when they have originated from unofficial distribution channels (Internet, bazaar, etc.) (14, 15). The data demonstrated that in Poland nurses and physicians should be trained in sharing information on counterfeit medicines with patients. Adequate training of nurses and physicians and other health care workers by the government as well as by relevant agencies in the detection of counterfeit drugs should be implemented. Healthcare professionals should support government actions aimed at warning patients against buying illegally imported medicine, locating potentially exposed patients, and assessing sources of suspicious medicine. Nurses and physicians should play a strategic role in limiting threats for health that result from environment and lifestyle.

Summing up, evidence from this study is exceptionally alarming because it demonstrates the size of the problem of counterfeit medicines in Poland. The insufficient awareness about counterfeit medicines by health care professionals needs to be improved as the presence of counterfeit drugs in the illegal trade in Poland is a large and real threat to public health. Therefore, health care professionals should play a significant role in the increasing awareness process for the benefit and safety of patients.

\section{CONCLUSIONS}

Results from this study suggest the following:

- It is necessary to increase the awareness of nurses and physicians about counterfeit medicines, due to difficulty in distinguishing counterfeit medicines from original drugs, particularly with the focus on detection and reporting of suspicious medicine from unknown sources.

- It is necessary to increase the awareness of lay persons of the threats related to the illegal medication trade.

- Further research is needed to determine the consequences of counterfeit drugs and to develop the rules for promoting the safety of health in Poland and neighbouring countries.

\section{Acknowledgement}

The authors would like to express thanks to the director and heads of hospital departments from Specialist Hospital in Sanok: Anesthesiology and Intensive Therapy Department, Internal Diseases Department, General Surgery Department, Orthopedics Department, and Pediatrics Department as well as directors of Non-public Basic Health Care Institutions in Rzeszow: Sano, Homo-Homini, Med.-Ned, Palomed were the study was conducted. 


\section{Funding statement}

Financial support is gratefully acknowledged from Institute of Nursing and Midwifery, Medical Department, University of Rzeszow, Poland.

\section{Conflict of interests}

None declared

\section{REFERENCES}

1. Juillet Y, Vlasto AP. Counterfeiting of medicinal drugs: issues and threats. Fundam Clin Pharmacol. 2005 Dec;19(6):621-4.

2. Larkin M. Combating counterfeit drugs online. Lancet Infect Dis 2006;6(9):552. doi:10.1016/S1473-3099(06)70573-4.

3. EurActiv. MEPs approve laws to curb counterfeit drugs [Internet]. Euractiv; 2011 [cited 2012 May 14]. Available from: http://www.euractiv. com/health/meps-approve-laws-curb-counterfeit-drugs-news-502192.

4. World Health Organization. Medicines. General information on counterfeit medicines [Internet]. Geneva: WHO; 2012 [cited 2012 May 14]. Available from: http://www.who.int/medicines/services/counterfeit/ overview/en/.

5. Wertheimer AI, Santella TM. Counterfeit drugs: defining the problem and finding solutions. Expert Opin Drug Saf. 2005 Jul;4(4):619-22.

6. Gibson L. Drug regulators study global treaty to tackle counterfeit drugs. BMJ. 2004 Feb 28;328(7438):486.
7. Rudolf PM, Bernstein IBG. Counterfeit drugs. N Engl J Med. 2004 Apr 1;350(14):1384-6.

8. Zarocostas J. WHO to set up international task force on counterfeit drugs. BMJ. 2006 Feb 25;332(7539):444

9. Cassels A. Institute of Medicine's new drug safety report: implications for Canada. CMAJ. 2006 Dec 5;175(12):1515-6.

10. European Commission. Taxation and customs union. Facts and figures [Internet]. Brussels: European Commission; 2012 [cited 2012 May 14]. Available from: http://ec.europa.eu/taxation customs/customs/ customs_controls/counterfeit_piracy/statistics/.

11. Newton P, Proux S, Green M, Smithuis F, Rozendaal J, Prakongpan S, et al Fake artesunate in southeast Asia. Lancet. 2001 Jun 16;357(9272):194850 .

12. Petrova GI. Monitoring of national drug policies - regional comparison between Bulgaria, Romania, Macedonia, Bosnia Herzegovina. Cent Eur J Public Health. 2001 Nov;9(4):205-13.

13. Master Page. News about Poland - the Polish Outlook. Poland targeted by internet Viagra scammers [Internet]. [cited 2012 May 14]. Available from: http:/www.masterpage.com.pl/outlook/200609/drugscam.html.

14. Ahmad K. WHO fights fake pharmaceuticals. Lancet Infect Dis. 2006;6(4):195

15. Combating counterfeit drugs. Lancet. 2008;371(9624):1551. doi:10.1016/ S0140-6736(08)60663-7.

16. World Health Organization. Counterfeit drugs: guidelines for the development of measures to combat counterfeit drugs. Geneva: WHO; 1999.

Received September 20, 2011 Accepted in revised form November 8, 2012 